\title{
PERANCANGAN SISTEM PENDUKUNG KEPUTUSAN PEMILIHAN PEGAWAI TELADAN MENGGUNAKAN METODE SAW (SIMPLE ADDITIVE WEIGHTING) BERBASIS WEB DI DINAS PENANAMAN MODAL DAN PELAYANAN TERPADU SATU PINTU KABUPATEN KEBUMEN
}

\author{
Ari Waluyo ${ }^{1 *}$, Nur Fais Irfandi \\ ${ }^{1,2}$ Program Studi Teknik Elektro, Politeknik Dharma Patria Kebumen, Kebumen, Indonesia \\ *Email: ari.hardware@yahoo.com
}

\begin{abstract}
Abstrak
Tujuan dari penelitian ini adalah untuk merancang sistem pendukung keputusan pemilihan pegawai teladan berbasis web menggunakan metode SAW (Simple Additive Weighting) di Dinas Penanaman Modal Dan Pelayanan Terpadu Satu Pintu Kabupaten Kebumen. Metode perhitungan yang di gunakan adalah metode $S A W$ (Simple Additive Weighting). Teknik pengumpulan data yang digunakan adalah dengan cara observasi, studi pustaka serta wawancara yang memiliki hubungan erat dengan pokok permasalahan serta metode pengembangan sistem yang digunakan adalah metode pengembangan sistem waterfall. Dari hasil penelitian yang dilakukan ditemukan permasalahan seperti kurang efektifnya pemilihan pegawai teladan yang dilakukan karena masih manual sehingga pemilihan pegawai teladan masih belum efisien. Adapun saran yang diberikan untuk mengatasi masalah tersebut adalah: 1) Perlu dilakukan sosialisasi dan training kepada bagian terkait terutama pada Subbagian Kepegawaian dan umum sebagai admin, agar sistem informasi dapat dimanfaatkan dengan baik, 2) Perlu adanya pengembangan sistem menjadi lebih baik lagi agar keamanan data dapat lebih terjaga.
\end{abstract}

Kata kunci: Sistem pendukung keputusan, Pegawai, Teladan, $S A W$

\begin{abstract}
The purpose of this research is to design decision support system of exemplary web-based employee using SAW (Simple Additive Weighting) method in capital investment and integrated service one door regency kebumen. Calculation method used is SAW (Simple Additive Weighting) method. Data collection techniques used is by observation, literature study and interviews that have a close relationship with the principal problems and methods of system development used is the method of waterfall system development. From the results of research conducted found the problems such as the lack of effective selection of exemplary employees who performed because it is still manual so that the selection of exemplary employees are still not efficient. The suggestions given to overcome the problem are: 1) Need to be socialized and training to the related sections, especially on the Subdivision of Personnel and general as admin, so that information systems can be utilized properly, 2) Need a better system development for data security can be more awake.
\end{abstract}

Keywords: Decision support system, Employee, Example, SAW

\section{PENDAHULUAN}

\subsection{Latar Belakang}

Teknologi yang semakin berkembang pada saat ini sangat mendukung kebutuhan suatu instansi. Baik untuk mewujudkan efektifitas dan efisiensi kerja maupun dalam meningkatkan pelayanan kepada masyarakat. Terutama sistem yang dapat membantu dalam memberikan informasi dan keputusan, agar informasi dan keputusan yang dikeluarkan instansi lebih bersifat relevan dan dapat diterima semua pihak. Pegawai merupakan sumber daya yang sangat penting untuk menentukan keberhasilan suatu satuan kerja. Pegawai yang berkualitas akan memudahkan satuan kerja dalam mencapai tujuannya, baik dalam hal pengabdian maupun pelayanan. Upaya meningkatkan kualitas kinerja seorang pegawai negeri yaitu adanya kenaikan pangkat.

Oleh karena hal tersebut perlu adanya pemberian predikat pegawai teladan sebagai memotivasi pegawai dan agar dapat memacu kinerja pegawai agar lebih bersemangat. Peran Sistem Pendukung Keputusan sangat dibutuhkan, guna meningkatkan efisiensi pengambilan keputusan. Peran Sistem Pendukung Keputusan akan membantu pihak manajemen dalam mencapai tujuan dari penilaian kinerja dalam menentukan pegawai teladan. Selama ini, penentuan pegawai teladan di Dinas Penanaman Modal 
Dan Pelayanan Terpadu Satu Pintu Kabupaten Kebumen dilakukan oleh petugas penilai yang berkoordinasi dengan kepala pimpinan. Sebelumnya terlebih dahulu dilakukan penghitungan manual tanpa menggunakan suatu sistem. Perhitungan yang dilakukan berupa penentuan kelayakan sebagai pegawai teladan. Sistem Pendukung Keputusan dapat membantu dalam menentukan penilaian atas hasil kerja pegawai untuk tujuan memilih pegawai teladan dengan menggunakan suatu metode dimana kriteria penilain yang digunakan adalah Profesionalisme, Religius Inovatif, Komitmen dan Akun Tabel.

Metode SAW (Simple Additive Weighting) sistematis dan tepat dalam proses pengambilan keputusan yang mampu menunjukkan nilai kompetensi pegawai sesuai dengan kriteria yang ditetapkan oleh pihak instansi atau pengambil keputusan berdasarkan analisa data yang sistematis untuk tujuan pemilihan pegawai teladan. Berdasarkan hal tersebut di atas, melatar belakangi peneliti untuk merancang dan membangun sebuah Sistem Pendukung Keputusan sebagai alat yang dapat memberikan kemudahan dan efektifitas dalam pengolahan data dalam menetukan keputusan sehingga dapat membantu dalam memberikan keputusan dengan hasil yang maksimal. Berdasarkan hal tersebut di atas, melatar belakangi peneliti membangun sebuah sistem kepegawaian sebagai alat yang dapat memberikan kemudahan dan efektifitas dalam pengolahan data dalam menetukan keputusan sehingga dapat membantu dalam memberikan keputusan.

\subsection{Pokok Permasalahan}

Berdasarkan latar belakang di atas pada Dinas Penanaman Modal Dan Pelayanan Terpadu Satu Pintu Kabupaten Kebumen, penulis merumuskan masalah yang timbul yaitu "Bagaimana membuat sistem pendukung keputusan pemilihan pegawai teladan menggunakan metode SAW (Simple Additive Weighting) berbasis web di Dinas Penanaman Modal Dan Pelayanan Terpadu Satu Pintu Kabupaten Kebumen yang secara terkomputerisasi agar menjadi lebih efektif dan efisien?".

\subsection{Pertanyaan Penelitian}

a. Factor - faktor apa saja yang menjadi pertimbangan untuk membuat sistem pendukung keputusan pemilihan pegawai teladan menggunakan metode SAW (Simple Additive Weighting) berbasis web di Dinas Penanaman Modal Dan Pelayanan Terpadu Satu Pintu Kabupaten Kebumen secara komputerisasi?

b. Apakah perlu melakukan simulasi agar dapat mengetahui efektivitas perhitungan degan menggunakan sistem pendukung keputusan pemilihan pegawai teladan menggunakan metode SAW (Simple Additive Weighting) dengan perhitungan yang manual di Dinas Penanaman Modal Dan Pelayanan Terpadu Satu Pintu Kabupaten Kebumen?

c. Apakah sistem ini dapat mempermudah pemilihan pegawai teladan menggunakan metode SAW (Simple Additive Weighting) yang saat ini masih menggunakan buku besar di Dinas Penanaman Modal Dan Pelayanan Terpadu Satu pintu kabupaten kebumen?

\subsection{Tujuan Penelitian}

a. Untuk mengetahui proses pemilihan pegawai teladan sekarang yang ada di di Dinas Penanaman Modal Dan Pelayanan Terpadu Satu pintu kabupaten kebumen.

b. Untuk mengetahui kendala apa yang ada di Dinas Penanaman Modal Dan Pelayanan Terpadu Satu pintu kabupaten kebumen apa bila proses pemilihan pegawai teladan sekarang yang masih berjalan secara manual.

c. Untuk mengetahui prosedur pemilihan pegawai teladan menggunakan metode saw (simple additive weighting) di Dinas Penanaman Modal dan Pelayanan Terpadi Satu Pintu Kabupaten Kebumen.

\subsection{Kegunaan Penelitian}

1. Bagi Peneliti

a. Dapat menambah ilmu sistem pendukung keputusan pemilihan pegawai teladan menggunakan metode SAW (Simple Additive Weighting) berbasis web di Dinas Penanaman Modal Dan Pelayanan Terpadu Satu Pintu Kabupaten Kebumen menggunakan Php Mysql.

b. Menambah ilmu pengetahuan dan wawasan tentang pemilihan pegawai teladan yang saat ini masih secara manual.

2. Bagi Instansi

Karena Proses pemilihan karyawan teladan yang dilakukan di Dinas Penanaman Modal Dan Pelayanan Terpadu Satu Pintu Kabupaten Kebumen masih secara manual, dengan diubahnya sistem secara terkomputerisasi mempermudah instansi dalam menentukan pemilihan pegawai teladan.

3. Bagi Pembaca 
Dapat menjadi bahan referensi bagi penulis lain, bagi yang berminat pada bidang sistem informasi kepegawaian terutama dalam pemilihan pegawai teladan.

\section{MATERI DAN METODE}

\subsection{Materi}

\section{a. Batasan Dan Analisa Masalah}

Batasan masalah pada sistem pendukung keputusan pemilihan pegawai teladan menggunakan metode SAW (Simple Additive Weighting) dengan perhitungan yang manual di Dinas Penanaman Modal Dan Pelayanan Terpadu Satu Pintu Kabupaten Kebumen adalah sebagai berikut:

1) Penulis hanya mengambil data yang berasal dari bagian sekertariat Kantor Dinas Penanaman Modal Dan Pelayanan Terpadu Kabupaten Kebumen yaitu data pegawai.

2) Sistem kepegawaian ini memfokuskan dalam pemilihan pegawai teladan menggunakan metode SAW (Simple Additive Weighting) yang dilakukan di Dinas Penanaman Modal Dan Pelayanan Terpadu Kabupaten Kebumen.

3) Kriteria yang dingunakan dalam penelitian menyesuaikan dengan intenal instansi.

4) Sistem yang di buat untuk membantu memberikan informasi dan pengambilan keputusan saja, sehingga keputusan yang sesungguhnya di ambil tetap berada pada bagian sekertariat.

\section{b. Teori Tentang Konsep, Analisis dan Perancangan}

1) Pengertian Sistem

"Sistem adalah suatu jaringan kerja dari prosedur- prosedur yang saling berhubungan, berkumpul bersama-sama untuk melakukan suatu kegiatan atau untuk menyelesaikan suatu sasaran yang tertentu."(Jogiyanto,2005;1). Sistem adalah kumpulan dari elemen-elemen yang berinteraksi untuk mencapai suatu tujuan tertentu." (Jogiyanto,2005;2)."Sistem adalah sekumpulan objek-objek yang saling berelasi dan berinteraksi serta hubungan antar objek bisa dilihat sebagai satu kesatuan yang dirancang untuk mencapai satu tujuan.”(Hanif Al Fatta.2007;3).

2) Sistem Pendukung Keputusan

Dalam buku "konsep dan aplikasi sistem pendukung keputusan" Sistem Pendukung Keputusan (Decision Support System) merupakan sistem informasi interaktif yang menyediakan informasi, pemodelan, dan pemanipulasian data. Sistem ini digunakan untuk membantu pengambilan keputusan dalam situasi yang semiterstruktur dan situasi yang tidak terstruktur, dimana tak seorangpun tahu secara pasti bagaimana keputusan seharusnya dibuat (Kusrini, 2007).

Sistem pendukung keputusan sebagai sebuah himpunan/kumpulan prosedur berbasis model untuk memproses data dan pertimbangan untuk membantu manajemen dalam pembuatan keputusannya (Kusrini, 2007).

Sistem Pendukung Keputusan merupakan system informasi interaktif yang menyediakan informasi, pemodelan, dan manipulasi data. Sistem itu digunakan untuk membantu pengambilan keputusan dalam situasi yang semiterstuktur dan situasi yang tidak terstruktur, dimana tak seorangpun tahu secara pasti bagaimana seharusnya keputusan seharusnya dibuat (Kusrini, 2007).

Berdasarkan definisi, sistem pendukung keputusan harus mencakup tiga komponen utama dari Database Management System (DBMS), Model-Base Management System (MBMS), dan antar muka pengguna. Arsitektur Decision Support System (DSS) disajikan pada gambar 1.

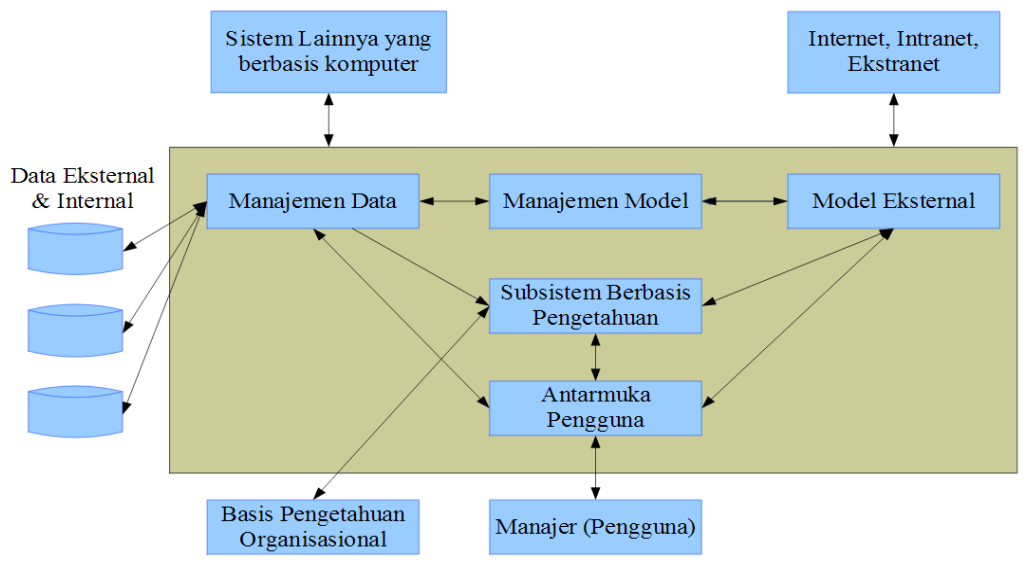

Gambar 1. Arsitektur Decision Support System (DSS) 
3) Pengertian Pegawai

Menurut Kamus Umum Bahasa Indonesia (Muhammad Ali), kata pegawai berarti orang yang bekerja pada pemerintah (Perusahaan dan sebagainya) Sedangkan negeri berarti "negara" atau "pemerintah" Jadi pegawai negeri adalah orang yang bekerja pada pemerintah atau negara".

4) Metode SAW (Simple Additive Weigting)

Metode Simple Additive Weighting (SAW) sering juga dikenal istilah metode penjumlahan terbobot.

Konsep dasar metode SAW adalah mencari penjumlahan terbobot dari rating kinerja pada setiap alternatif pada semua atribut (Fishburn, 1967) (MacCrimmon, 1968).

Metode SAW membutuhkan proses normalisasi matriks keputusan (X) ke suatu skala yang dapat diperbandingkan dengan semua rating alternatif yang ada. Metode ini merupakan metode yang paling terkenal dan paling banyak digunakan dalam menghadapi situasi Multiple Attribute Decision Making (MADM). MADM itu sendiri merupakan suatu metode yang digunakan untuk mencari alternatifoptimal dari sejumlah alternatif dengan kriteria tertentu.

Langkah Penyelesaian Simple Additive Weighting (SAW) sebagai berikut :

a) Menentukan kriteria-kriteria yang akan dijadikan acuan dalam pengambilan keputusan, yaitu Ci.

b) Menentukan rating kecocokan setiap alternatif pada setiap kriteria.

c) Membuat matriks keputusan berdasarkan kriteria(Ci), kemudian melakukan normalisasi matriks berdasarkan persamaan yang disesuaikan dengan jenis atribut (atribut keuntungan ataupun atribut biaya) sehingga diperoleh matriks ternormalisasi $\mathrm{R}$.

d) Hasil akhir diperoleh dari proses perankingan yaitu penjumlahan dari perkalian matriks ternormalisasi $\mathrm{R}$ dengan vektor bobot sehingga diperoleh nilai terbesar yang dipilih sebagai alternatif terbaik (Ai) sebagai solusi.

Formula untuk melakukan normalisasi matriks disajikan pada gambar 2.

$$
r_{i j}=\left\{\begin{array}{l}
\frac{r_{i j}}{\operatorname{Max} x_{i j}} \text { jika } j \text { adalah atribut (benefit) } \\
\frac{\operatorname{Min} x_{i j}}{x_{i j}} \text { jika } j \text { adalah atribut biaya (cost) }
\end{array}\right.
$$

Gambar 2. Normalisasi Matriks

Dimana :

rij = rating kinerja ternormalisasi

Maxij = nilai maksimum dari setiap kolom

Minij = nilai minimum dari setiap kolom

$\mathrm{Xij}=$ baris dan kolom dari matriks

Dengan rij adalah rating kinerja ternormalisasi dari alternatif Ai pada atribut

$\mathrm{Cj} ; \mathrm{i}=1,2, \ldots \mathrm{m}$ dan $\mathrm{j}=1,2, \ldots, \mathrm{n}$.

Nilai preferensi untuk setiap alternatif (Vi) disajikan pada gambar 3.

$$
V_{i}=\sum_{j=1}^{n} W_{j} x_{i j}
$$

Dimana:

Gambar 3. Nilai preferensi untuk setiap alternatif (Vi)

$\mathrm{Vi}=$ Nilai akhir dari alternative

wj = Bobot yang telah ditentukan

rij $=$ Normalisasi matriks

Nilai Vi yang lebih besar mengindikasikan bahwa alternative Ai lebih terpilih

a) Menentukan kriteria-kriteria yang akan dijadikan acuan dalam pengambilan keputusan.

b) Menentukan rating kecocokan setiap alternatif pada setiap kriteria.

c) Membuat matriks keputusan berdasarkan kriteria, kemudian melakukan normalisasi matriks berdasarkan persamaan yang disesuaikan dengan jenis atribut (atribut keuntungan ataupun atribut biaya) sehingga diperoleh matriks ternormalisasi $\mathrm{R}$.

d) Hasil akhir diperoleh dari proses perankingan yaitu penjumlahan dari perkalian matriks ternormalisasi $\mathrm{R}$ dengan vektor bobot sehingga diperoleh nilai terbesar yang dipilih sebagai alternatif terbaik sebagai solusi (Henry. 2009).

5) Profesional

a) Menjalankan Tugas Dengan Baik

b) Melakukan Kerja Sama Dengan Berbagai Pihak 
c) Loyal

d) Disiplin

e) Meningkatkan Kompetisi Dalam Berkerja

f) Responsiv

g) Bertoreransi Pada Pelayanan Sehingga Setiap Pelanggan Mendapat Kepuasan

6) Religius
a) Beribadah Sesuai Agama Yang Dianut
b) Keteladanan
c) Saling Menghormati
d) Amanah
e) Ikhlas Dalam Menjalankan Tugas
f) Jujur
g) Bersahaja

7) Komitmen
a) Kemampuan Berkerja Keras
b) Kemampuan Menyelesaikan Tugas
c) Pengabdian Yang Tinggi
d) Fokus Pada Pekerjaan
e) Konsisten

8) Inovatif
a) Berwawasa Luas
b) Cepat Beradaptasi
c) Berwawasan Luas
d) Kreatif
e) Berpandangan Jauh Kedepan

9) Akun Tabel
a) Taat Terhadap Perundang Undangan
b) Memenuhi Target Kerja Yang Telah Ditetapkan
c) Mempertanggung Jawabkan Sumber Daya Yang Digunakan
d) Teliti Dan Akurat
e) Transpran
f) Berkualitas

10) Unified Modelling Language (UML)

Unified Modelling Language (UML) adalah salah satu alat bantu yang sangat handal di dunia pengembangan sistem yang berorientasi obyek (Munawar,2005:17).

\subsection{Metode}

\section{a. Teknik Pengumpulan Data}

Dalam penulisan skripsi ini penulis menggunakan teknik sebagai berikut:

1) Observasi

2) Studi Puataka

3) Wawancara

b. Metode Pengembangan Perangkat Lunak

Pengembangan sistem pendukung keputusan pemilihan pegawai teladan menggunakan metode saw (simple additive weighting) berbasis web di Dinas Penanaman Modal Dan Pelayanan Terpadu Satu Pintu Kabupaten Kebumen ini akan menggunakan metode waterfall yang merupakan metode pengembangan yang sistematik dan sekuensial yang di mulai pada tingkat dan kemajuan sistem sampai pada analisis, desain, kode, test dan pemeliharaan. Berikut ini adalah tahapan model waterfall (Roger S.Pressman,2002:37)
1) Analisis
2) Desain
3) Code
4) Pengujian
5) Pemeliharaan 


\section{HASIL DAN PEMBAHASAN}

3.1. Gambaran Umun DPMPTSP

\section{a. Sejarah DPMPTSP}

Dinas Penanaman Modal Dan Pelayanan Terpadu Satu Pintu (DPMPTSP) Kab. Kebumen adalah Badan Aparatur Daerah khusunya Kabupaten Kebumen yang mengelola tentang perizinan usaha yang teradapat di Kabupaten Kebumen. Badan ini telah berganti nama sebanyak lima kali sejak berdirinya Dinas tersebut. Dari pertama kali awal mula DPMPTSP adalah bernama OSS yaitu One Stop Service dimna OSS ini masih menginduk pada BPPKAD Kab. Kebumen, yang dulu masih bernama dari Dippenda menjadi Kappenda dan yang sekarang lebih dikenal dengan BPKAD Kab. Kebumen. OSS menginduk pada BPKAD pada periode BPKAD bernama Kappenda yaitu pada tahun 2008. Dari 2008 berjalan satu bulan DPMPTSP berganti nama kembali menjadi KPPT atau Kantor Pelayanan Perizinan Terpadu yang pada saat itu sudah menjadi Kantor independen atau sudah tidak menginduk lagi pada BPPKAD sejak di tetapkanya Peraturan Dalam Negeri dan Keputusan Presiden bahwa setiap Kantor / Dinas harus berdiri sendiri. KPPT ini memiliki periode yaitu kurang lebih 4 tahun sebelum berganti nama kembali yaitu pada tahun 2012. Pada tahun 2012 ini KPPT berganti nama kembali menjadi KPPT dan PM atau Kantor Pelayanan Perizinan Terpadu dan Penanaman Modal. Periode ini bertahan selama kurang lebih 2 tahun setelahpenetapan. Periode ini terhitung yaitu dari tahun 2012 sampai 2014.

Pada tahun 2014 terdapat perubahan kembali, yaitu perubahan yang keempat setelah penetapan Peraturan Menteri dalam Negeri Nomor 64 Tahun 2007 tentang Teknis Organisasi dan Tata Kerja Inspektorat Provinsi dan Kabupaten Kota serta Peraturan Presiden Nomor 27 Tahun 2009 tentang Pelayanan Terpadu Satu Pintu di Bidang Peanaman Modal sehingga dari awal mula KPPT dan PM berganti nama menjadi BPMPT atau Badan Penanaman Modal dan Perizinan Terpadu Kabupaten Kebumen terhitung sejak Tahun 2015 sampai 2016.

Pada tahun 2016 terdapat perubahan kembali, yaitu perubahan yang kelima setelah penetapan Peraturan Daerah Nomor 07 Tahun 2016 tentang Pembentukan Dan Susunan Perangkat Daerah Kabupaten P Berdasarkan kewenangannya, Bupati dalam menyelenggarakan pemerintahan daerah dibantu oleh Perangkat Daerah yang terdiri dari unsur staf yang membantu penyusunan kebijakan, unsur pelaksana otonomi, unsur pendukung tugas kepala daerah dalam penyusunan dan pelaksanaan kebijakan daerah yang bersifat spesifik serta staf ahli yang melaksanakan tugas dan fungsi di luar tugas Perangkat Daerah sehingga BPMPT berubah nama menjadi DPMPTSP terhitug dari 01 januari 2017 hingga saat ini.

\section{b. Tugas Pokok DPMPTSP}

Dinas Penanaman Modal Dan Perizinan Terpadu Sau Pintu (DPMPTSP) Kab. Kebumen mempunyai tugas pokok melaksanakan koordinasi dan menyelenggarakan pelayanan administrasi dibidang perizinan secara terpadu dengan prinsip koordinasi, integrasi, sinkronisasi, keamanan dan kepastian.

\subsection{Uraian Prosedur}

Pada proses ini bertujuan untuk mengetahui langkah-langkah atau proses apa saja yang telah dilakukan pada sistem yang sedang berjalan.

a. Use case Diagram yang Berjalan

Use case sistem yang berjalan disajikan pada gambar 4 .

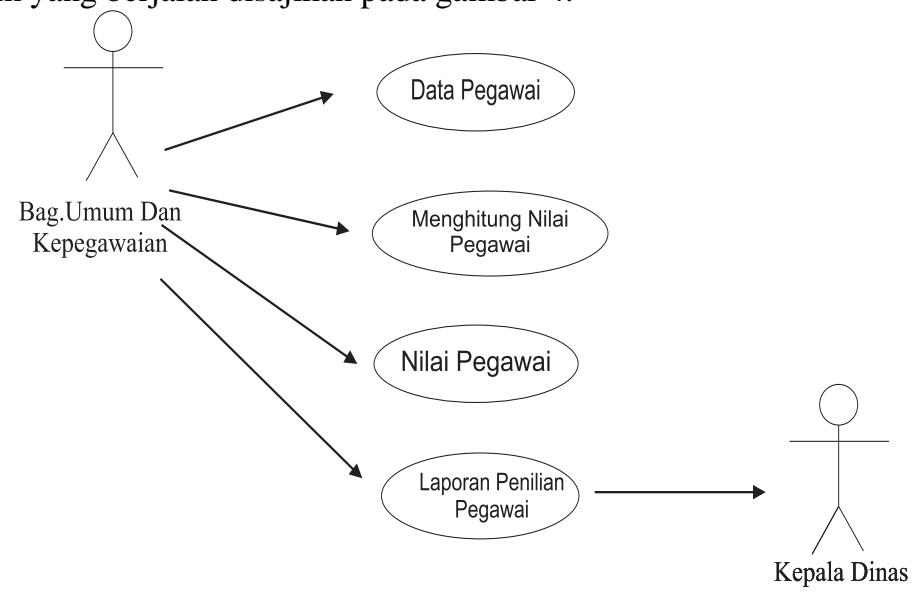

Gambar 4. Use Case Sistem yang Berjalan 
b. Aktivity Diagram yang sedang berjalan

Aktivitiy sistem yang berjalan disajikan pada gambar 5 .

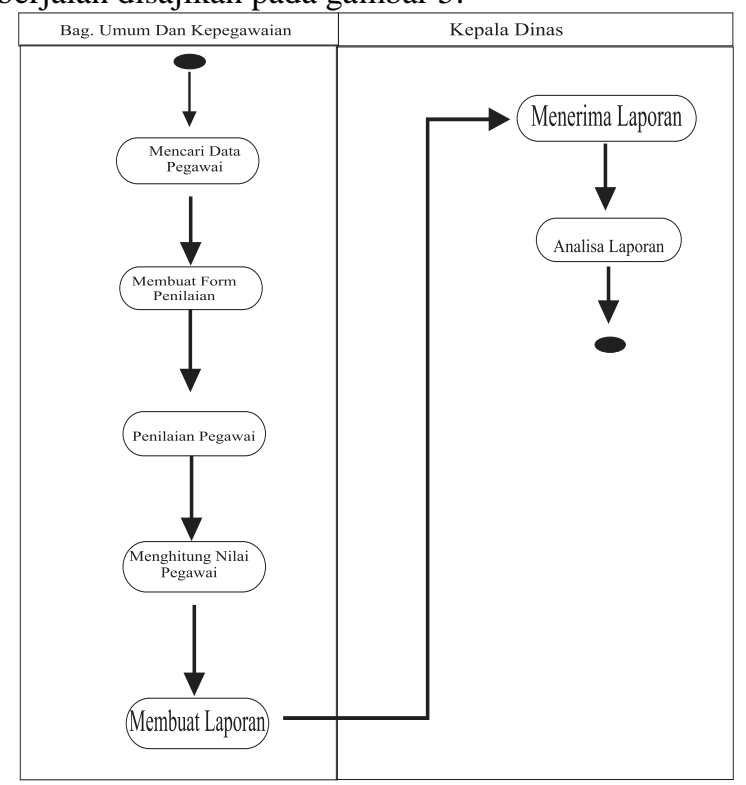

c. Kelemahan sistem yang berjalan

Gambar 5. Aktivitiy Sistem yang Berjalan

1) Kurangnya efektifitas dalam memilih pegawai teladan/terbaik di DPMPTSP yang masih manual menggunakan buku.

2) Pemilihan masih di nilai belum efisien dan jika hasil pemilihan pegawai teladan/terbaik masih harus mencari data pegawai dan menghitung semua nilai secara manual sehingga mengurangi efisiensi waktu.

3) Metode yang di gunakan dalam pemilihan pegawai terbaik/teladan masih belum jelas.

d. Upaya pemecahan permasalahan

1) Pembuatan aplikasi sistem pendukung keputusan pemilihan pegawai teladan menggunakan metode SAW (Simple Additive Weighting) berbasis web di Dinas Penanaman Modal Dan Pelayanan Terpadu Satu Pintu Kabupaten Kebumen yang memfokuskan dalam pemilihan pegawai terbaik/teladan diharapkan dapat mempermudah Subbagian Umum dan Kepegawaian dalam memilih pegawai terbaik/teladan.

2) Dalam sistem ini dapat mengurangi kesalahan dalam perhitungan ketika menjumlah nilai yang di dapat oleh pegawai.

3) Metode SAW (Simple Additive Weighting) Kebumen yang digunakan untuk menilai pegawai dapat membantu memutuskan dalam pemilihan pegawai teladan.

\subsection{Kesimpulan Hasil Analisis}

Dari hasil analisis yang telah di lakukan penulis dapat disimpulkan bahwa proses pemilihan pegawai teladan yang dilakukan di Dinas Penanaman Modal Dan Pelayanan Terpadu Kabupaten Kebumen masih manual yaitu dengan menulisnya dalam buku dan menghitung nilai yang di diperoleh setiap pegawai sehingga waktu yang dibutuhkan dalam memilih pegawai terbaik/teladan masih membutuhkan waktu yang lama.

Dari hal tersebut penulis memiliki rancangan sistem pendukung keputusan pemilihan pegawai teladan menggunakan metode SAW (Simple Additive Weighting) berbasis web di Dinas Penanaman Modal Dan Pelayanan Terpadu Satu Pintu Kabupaten Kebumen.

\subsection{Perancangan Sistem}

\section{a. Functional Design (Rancangan Fungsional)}

Rancangan fungsional menjelaskan tentang fungsi-fungsi apa saja yang dapat dilakukan oleh sistem. Pada perancangan sistem digambarkan sistem yang akan dibangun sebelum dilakukan pengkodean dalam suatu bahasa pemrograman. Dari hasil analisa sistem baru dapat dibuat suatu rancangan sistem, maka diusulkan perancangan sebagai berikut: 


\section{1) Use Case Diagram}

Use case diagram adalah diagram yang menggambarkan interaksi antara sistem dan aktor. Use case diagram disajikan pada gambar 6 .

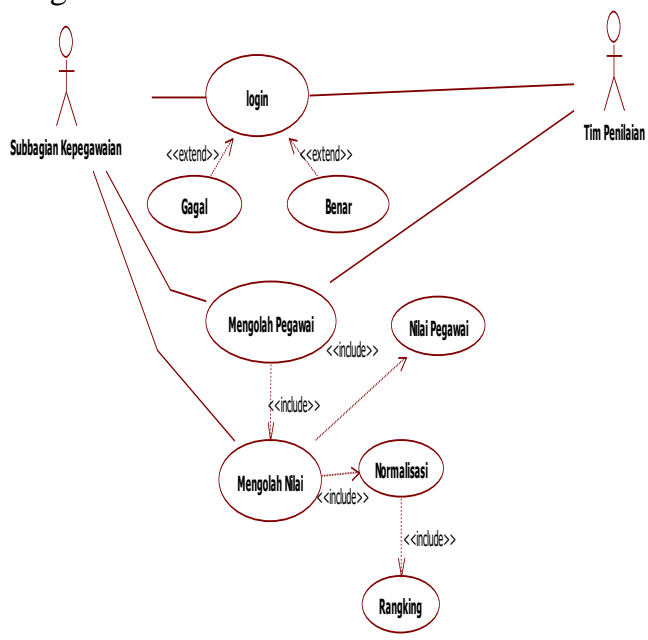

Gambar 6. Use Case Diagram

\section{2) Class Diagram}

Diagram ini memperlihatkan himpunan kelas-kelas, antarmuka, kolaborasi-kolaborasi, serta relasi-relasi. Tampilan class diagram disajikan pada gambar 7.

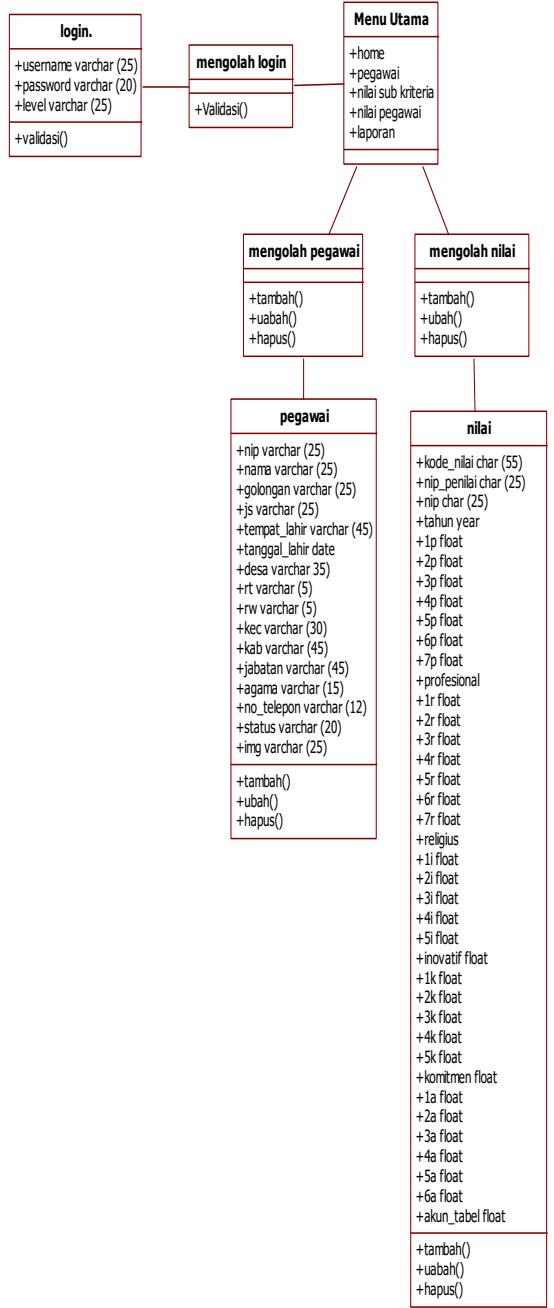

Gambar 7. Class Diagram 


\section{3) Aktivity Diagram}

Aktivity diagram adalah tipe khusus dari diagram state yang memperlihatkan aliran dari suatu aktifitas lainnya dalam suatu sistem.

a) Aktivity Diagram Sub Bag Umum dan Kepegawaian

Aktivity diagram sub bag umum dan kepegawaian disajikan pada gambar 8 .

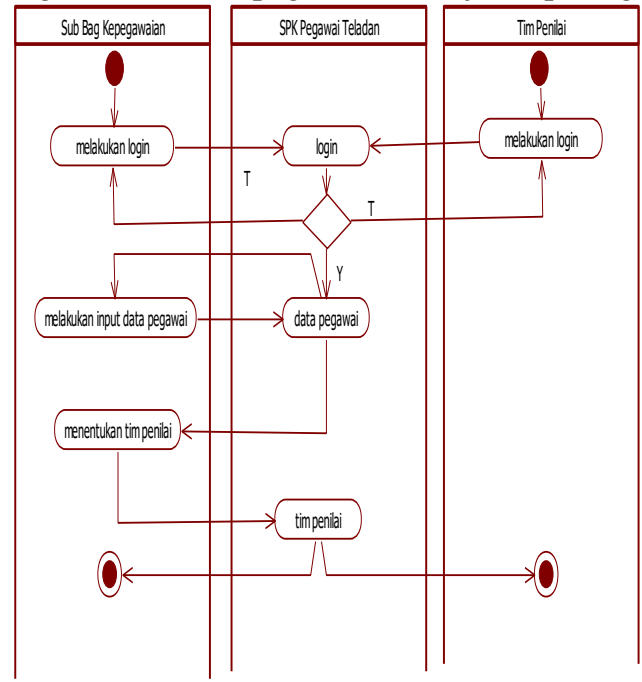

Gambar 8. Aktivity Diagram Sub Bag Umum dan Kepegawaian

b) Aktivity Diagram Tim Penilai

Aktivity diagram tim penilai disajikan pada gambar 9.

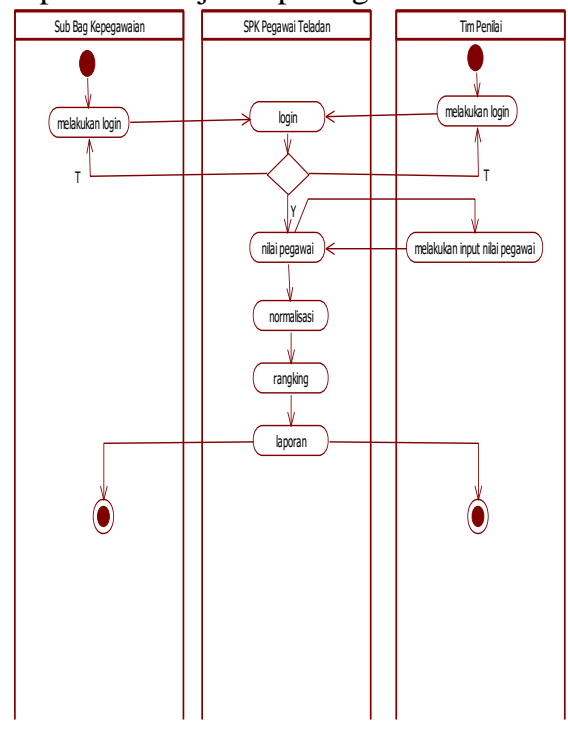

Gambar 9. Aktivity Diagram Tim Penilai

\section{4) Deployment Diagram}

Deployment diagram disajikan pada gambar 10.

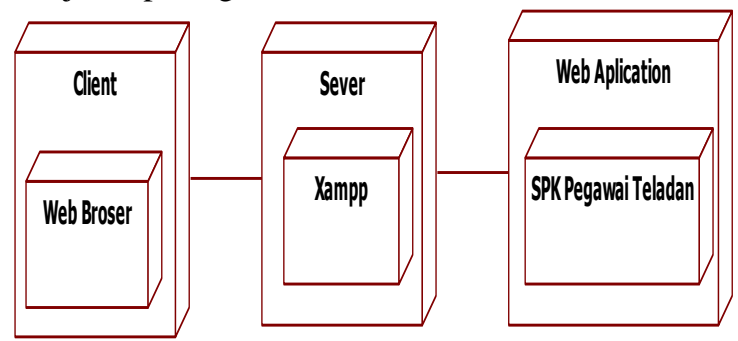

Gambar 10. Deployment Diagram 
5) Component Diagram

Component diagram disajikan pada gambar 11.

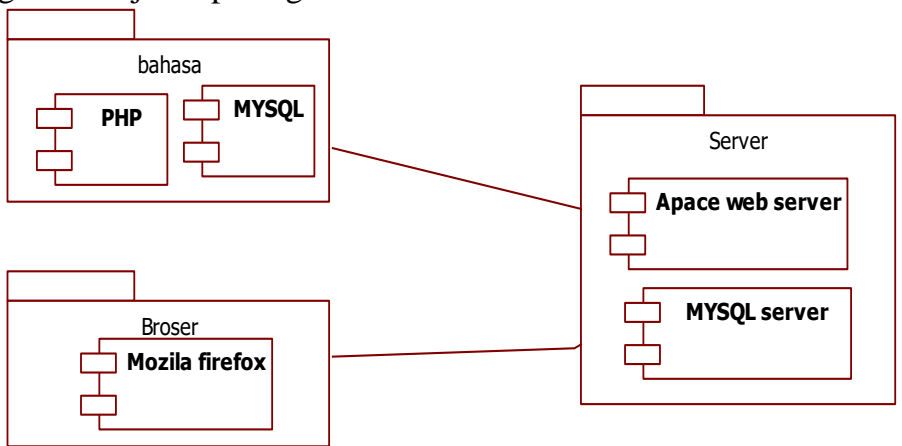

Gambar 11. Component Diagram

\section{b. Rancangan Basis Data}

Database digunakan untuk sekumpulan data yang berkaitan dengan satu sama lain, dan menjadi satu organisasi sehingga dapat dimanfatkan dengan cepat dan mudah untuk berbagai macam kebutuhan yang bersangkutan dengan pengolahan data. Dalam web ini menggunakan satu database dengam nama saw. Dalam database tersebut terdapat beberapa tabel, adapun tabel tersebut adalah sebagai berikut :

1) Tabel Login

2) Tabel Pegawai

3) Tabel Nilai

\section{c. Rancangan Dialog Layar}

1) Form Login

Form login disajikan pada gambar 12.

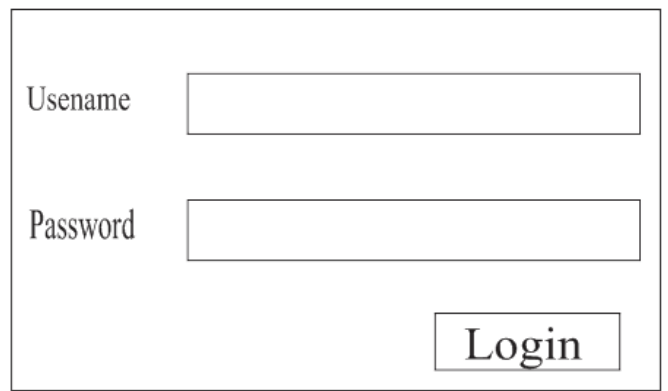

Gambar 12. Form Login

\section{2) Form Home}

Form home disajikan pada gambar 13.

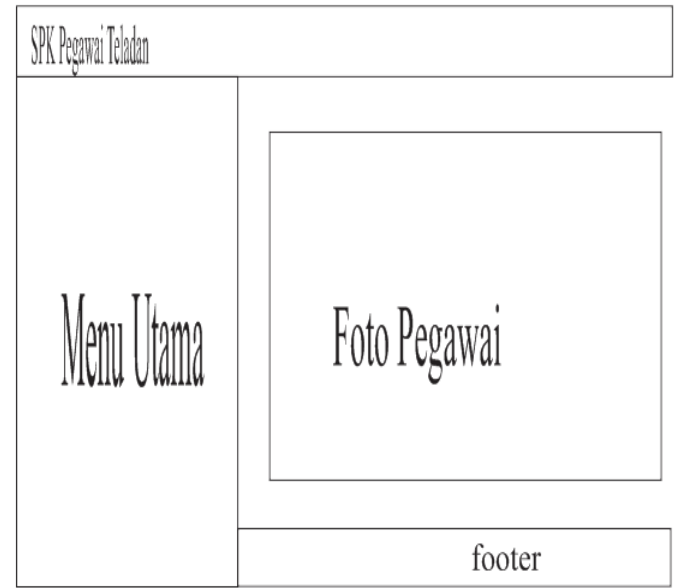

Gambar 13. Form Home 
3) Tabel Data Pegawai

Tabel data pegawai disajikan pada gambar 14 .

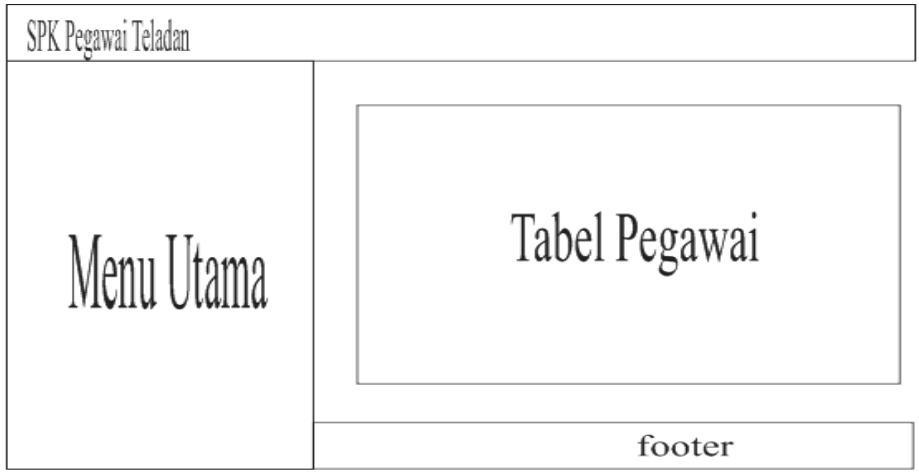

Gambar 14. Tabel Data Pegawai

4) Form Profil Pegawai

Form profil pegawai disajikan pada gambar 15 .

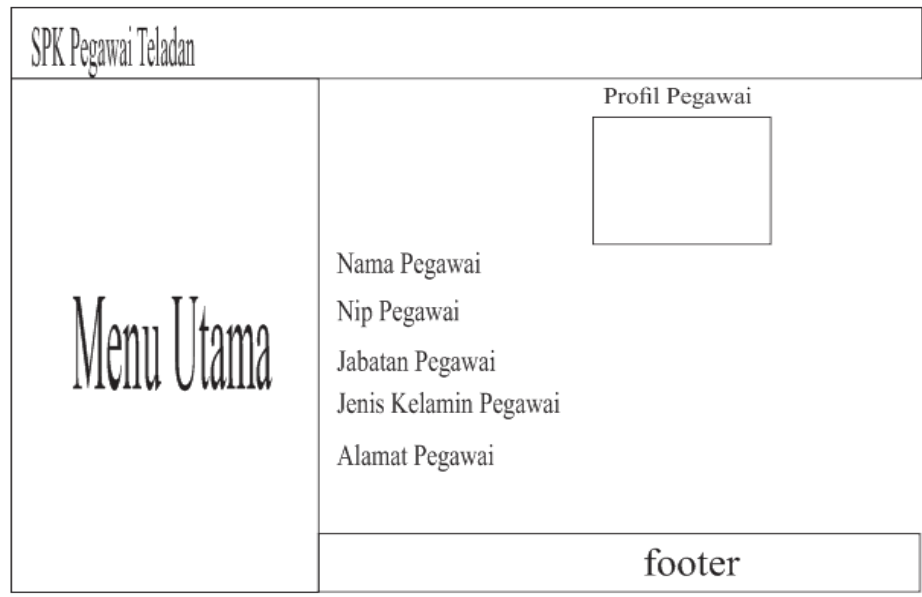

Gambar 15. Form Profil Pegawai

\section{d. Implementasi dan Interface Sistem}

Implementasi interface merupakan penerapan perancangan format tampilan yang telah dibuat sebelumnya dalam perancangan pengembangan sistem. Adapun implementasi interface dari perancangan sistem pendukung keputusan pemilihan pegawai teladan menggunakan metode SAW (Simple Additive Weighting) berbasis web di Dinas Penanaman Modal Dan Pelayanan Terpadu Satu Pintu Kabupaten adalah sebagai berikut :

1) Login

Tampilan login disajikan pada gambar 16.

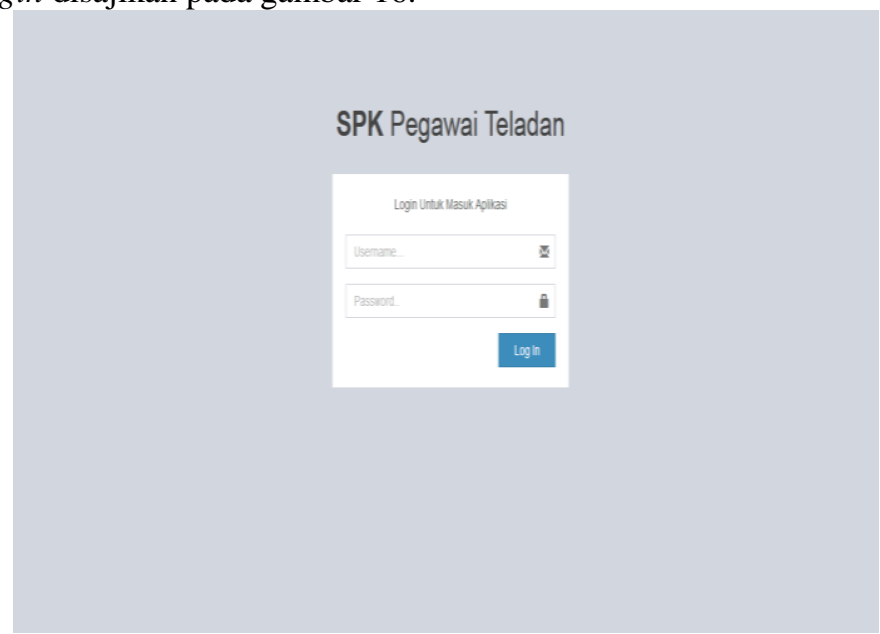

Gambar 16. Form Login 
2) Home

Tampilan Home disajikan pada gambar 17.

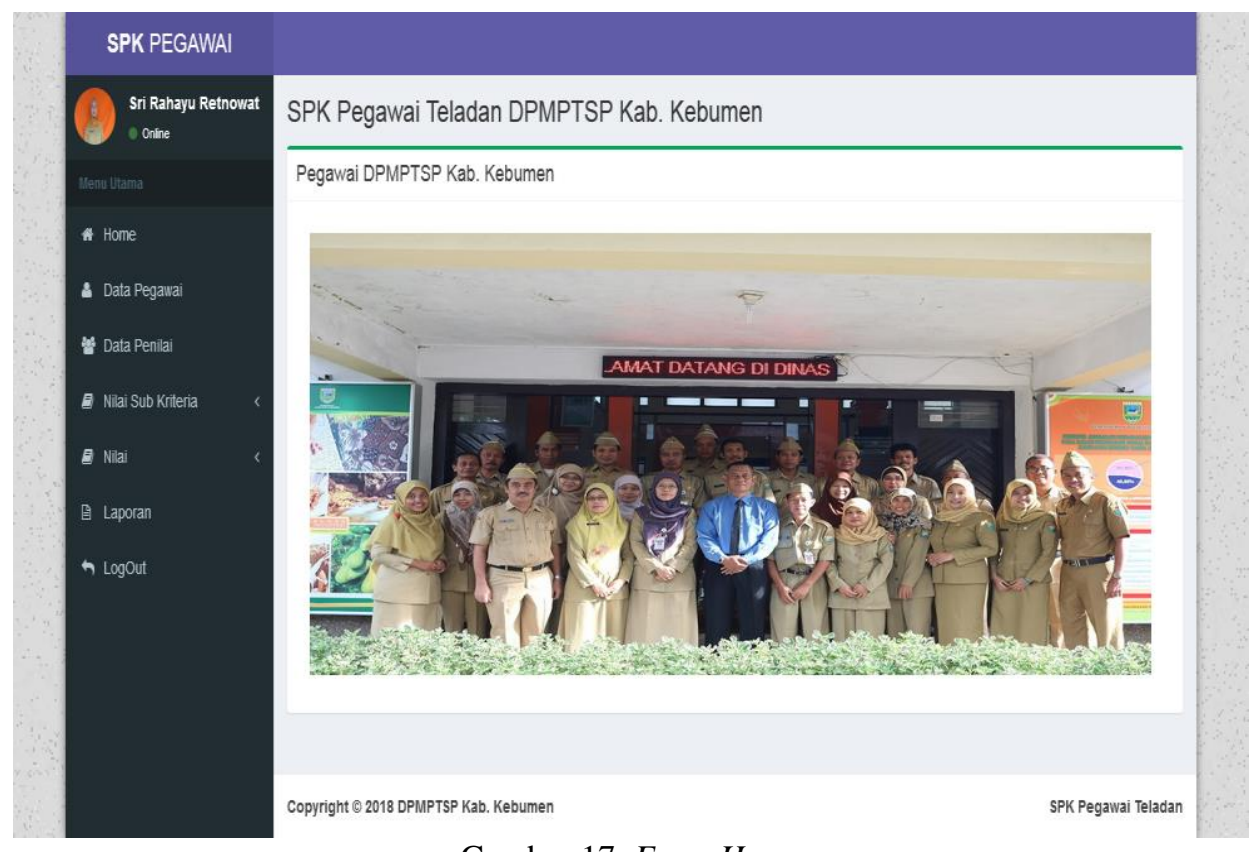

Gambar 17. Form Home

3) Form Data Pegawai

Tampilan form data pegawai disajikan pada gambar 18 .

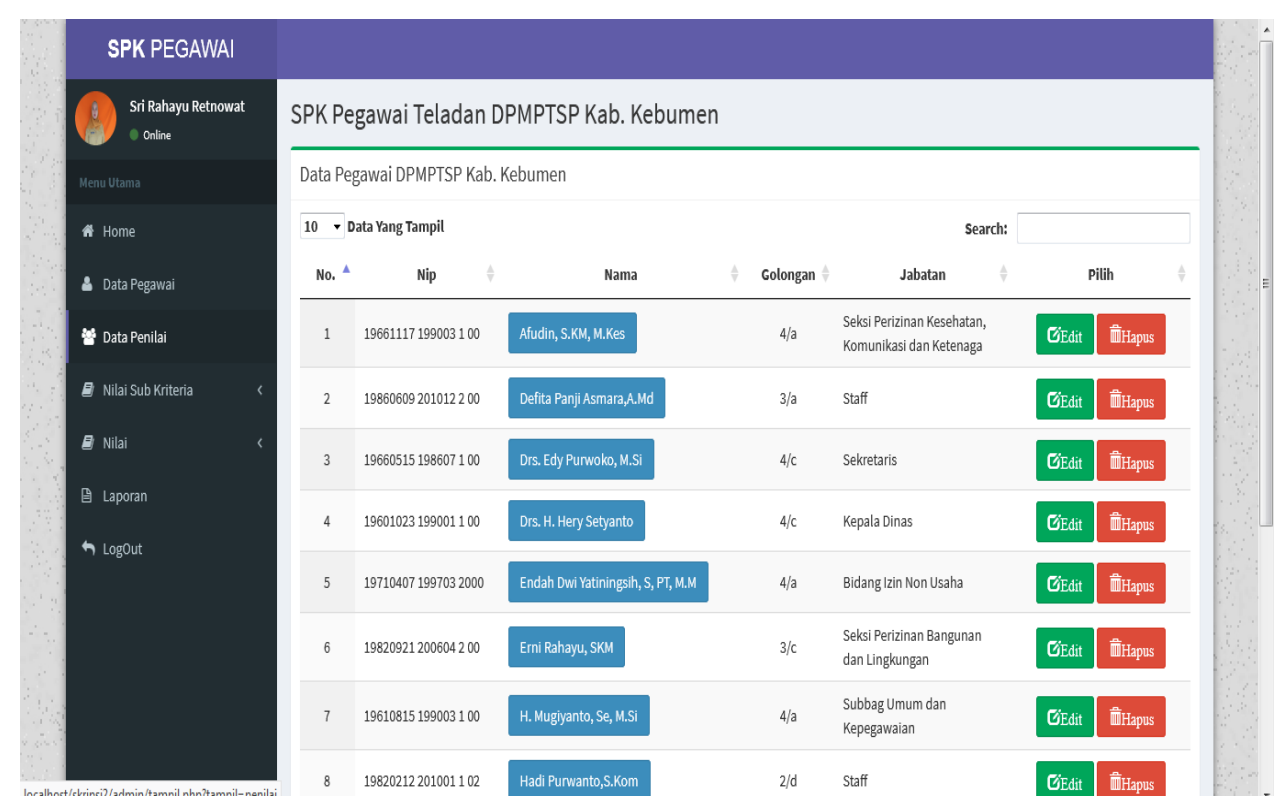

Gambar 18. Form Data Pegawai 
4) Form Profil Pegawai

Tampilan form profil pegawai disajikan pada gambar 19.

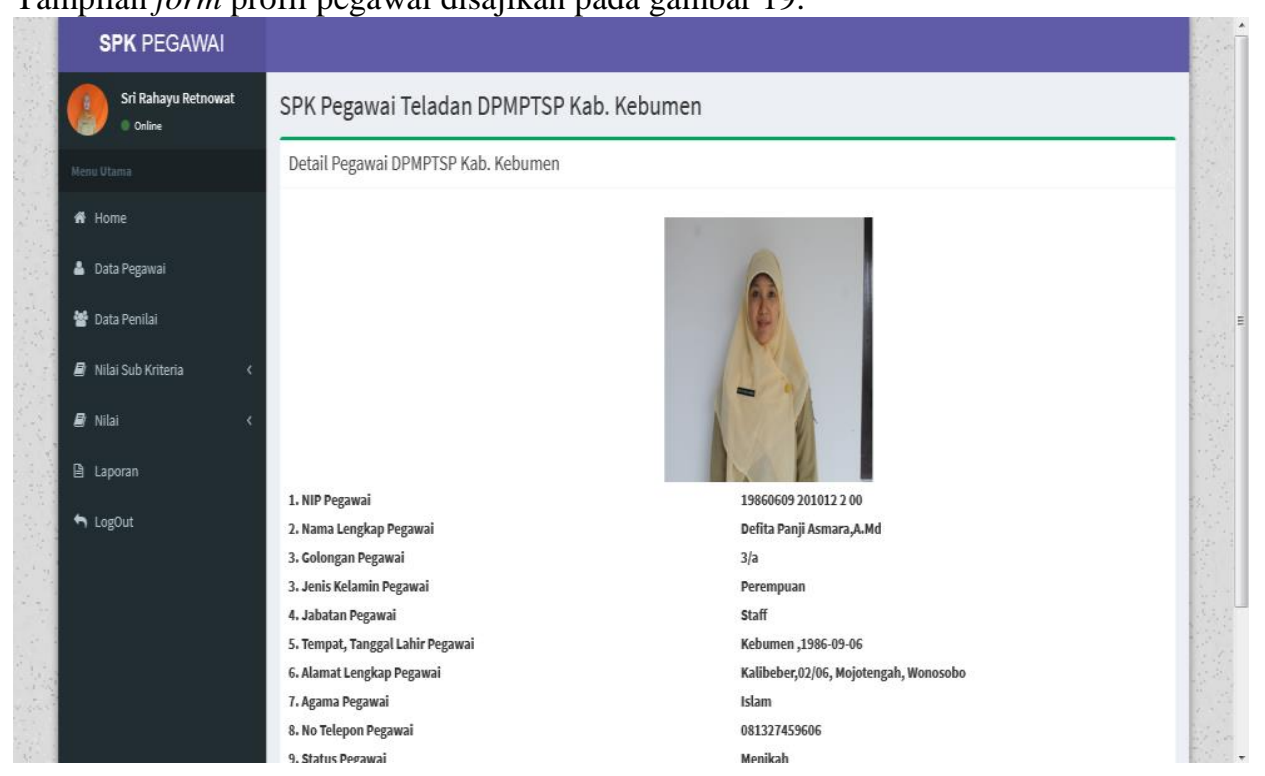

Gambar 19. Form Profil Pegawai

\subsection{Pengujian Sistem}

Pengujian sistem merupakan bagian yang penting dalam siklus pengembangan perangkat lunak. Pengujian dilakukan untuk menjamin kualitas dan mengetahui kelemahan dari perangkat lunak. Tujuan dari pengujian ini adalah untuk menjamin bahwa perangkat lunak yang dibangun memiliki kualitas yang baik, yaitu untuk mempresentasikan kajian pokok dari spesifik, analisis, perancangan dan pengkodean perangkat lunak itu sendiri.

Pengujian perangkat lunak pada penelitian ini menggunakan metode pengujian blackbox. Pengujian blackbox adalah pengujian aspek fundamental sistem tanpa memperhatikan struktur logika internal perangkat lunak. Metode ini digunakan untuk mengetahui apakah perangkat lunak berfungsi dengan benar. Pengujian blackbox merupakan metode perancangan data uji yang didasarkan pada spesifikasi perangkat lunak. 
a. Pengujian terdadap form login

Pengujian terhadap form login disajikan pada tabel 1 .

Tabel 1. Pengujian terdadap form login

\begin{tabular}{|c|c|c|c|c|c|}
\hline NO & Skenario Pengujian & Test Case & $\begin{array}{c}\text { Hasil yang } \\
\text { diharapkan }\end{array}$ & $\begin{array}{c}\text { Hasil } \\
\text { Pengujian }\end{array}$ & Diterima \\
\hline 1. & $\begin{array}{l}\text { Username dan } \\
\text { password tidak diisi } \\
\text { kemudian klik tombol } \\
\text { login }\end{array}$ & $\begin{array}{l}\text { Username } \\
\text { (kosong) } \\
\text { Paswrod } \\
\text { (Kosong) }\end{array}$ & $\begin{array}{l}\text { Sistem akan } \\
\text { menolak }\end{array}$ & $\begin{array}{c}\text { Sistem akan } \\
\text { menolak }\end{array}$ & Diterima \\
\hline 2. & $\begin{array}{l}\text { Username dan } \\
\text { password tidak diisi } \\
\text { kemudian klik tombol } \\
\text { login }\end{array}$ & $\begin{array}{l}\text { Username } \\
\text { admin dan } \\
\text { Password } \\
\text { (Kosong) }\end{array}$ & $\begin{array}{l}\text { Sistem akan } \\
\text { menolak }\end{array}$ & $\begin{array}{c}\text { Sistem akan } \\
\text { menolak }\end{array}$ & Diterima \\
\hline 3. & $\begin{array}{l}\text { Username dan } \\
\text { password tidak diisi } \\
\text { kemudian klik tombol } \\
\text { login }\end{array}$ & $\begin{array}{c}\text { Username } \\
\text { (Kosong) } \\
\text { Password 123 }\end{array}$ & $\begin{array}{l}\text { Sistem akan } \\
\text { menolak }\end{array}$ & $\begin{array}{l}\text { Sistem akan } \\
\text { menolak }\end{array}$ & Diterima \\
\hline 4. & $\begin{array}{l}\text { Mengetikan Username } \\
\text { dan password diisi } \\
\text { kemudian klik tombol } \\
\text { login }\end{array}$ & $\begin{array}{c}\text { Username } \\
\text { Admin } \\
\text { password } 123\end{array}$ & $\begin{array}{l}\text { Sistem akan } \\
\text { menerima } \\
\text { akses login } \\
\text { admin }\end{array}$ & $\begin{array}{l}\text { Sistem akan } \\
\text { menerima } \\
\text { akses login } \\
\text { admin }\end{array}$ & Diterima \\
\hline 5. & $\begin{array}{l}\text { Mengetikan Username } \\
\text { dan password diisi } \\
\text { kemudian klik tombol } \\
\text { login }\end{array}$ & $\begin{array}{c}\text { Username } \\
\text { pegawai } \\
\text { password } 123\end{array}$ & $\begin{array}{l}\text { Sistem akan } \\
\text { menerima } \\
\text { akses login } \\
\text { pegawai } \\
\end{array}$ & $\begin{array}{l}\text { Sistem akan } \\
\text { menerima } \\
\text { akses login } \\
\text { pegawai } \\
\end{array}$ & Diterima \\
\hline
\end{tabular}

b. Pengujian terhadap Form Input Pegawai

Pengujian terdadap form input pegawai disajikan pada tabel 2.

Tabel 2. Pengujian terdadap Form Input Pegawai

\begin{tabular}{|c|c|c|c|c|c|}
\hline NO & Skenario Pengujian & Test Case & $\begin{array}{l}\text { Hasil yang } \\
\text { diharapkan }\end{array}$ & $\begin{array}{c}\text { Hasil } \\
\text { Pengujian } \\
\end{array}$ & Diterima \\
\hline 1. & Isi data pegawai & $\begin{array}{l}\text { Data masuk ke } \\
\text { form isian data }\end{array}$ & $\begin{array}{c}\text { Pengisian } \\
\text { sesuai dengan } \\
\text { yang } \\
\text { diharapkan }\end{array}$ & $\begin{array}{c}\text { Pengisian } \\
\text { sesuai } \\
\text { dengan yang } \\
\text { diharapkan }\end{array}$ & Diterima \\
\hline 2. & Klik tombol simpan & $\begin{array}{l}\text { Data disimpan } \\
\text { masuk ke } \\
\text { database dan } \\
\text { muncul pesan } \\
\text { data telah } \\
\text { disimpan }\end{array}$ & $\begin{array}{c}\text { Tombol } \\
\text { simpan sesuai } \\
\text { yang } \\
\text { diharapkan }\end{array}$ & $\begin{array}{c}\text { Tombol } \\
\text { simpan } \\
\text { sesuai yang } \\
\text { diharapkan }\end{array}$ & diterima \\
\hline 3. & Klik tombol edit & $\begin{array}{l}\text { Data yang ada } \\
\text { didatabase } \\
\text { telah disimpan } \\
\text { dan akan } \\
\text { diedit }\end{array}$ & $\begin{array}{c}\text { Tombol diedit } \\
\text { sesuai yang } \\
\text { diharapkan }\end{array}$ & $\begin{array}{c}\text { Tombol } \\
\text { diedit sesuai } \\
\text { yang } \\
\text { diharapkan }\end{array}$ & diterima \\
\hline 4. & Klik tombol hapus & $\begin{array}{c}\text { Data } \\
\text { didatabase } \\
\text { akan terhapus } \\
\text { dan muncul } \\
\text { pesan data } \\
\text { berhasil } \\
\text { dihapus }\end{array}$ & $\begin{array}{c}\text { Tombol hapus } \\
\text { sesuai yang } \\
\text { diinginkan }\end{array}$ & $\begin{array}{c}\text { Tombol } \\
\text { hapus sesuai } \\
\text { yang } \\
\text { diinginkan }\end{array}$ & Diterima \\
\hline 5. & Klik tombol search & $\begin{array}{c}\text { Admin } \\
\text { mencari data } \\
\text { yang } \\
\text { diperlukan }\end{array}$ & $\begin{array}{l}\text { Sistem akan } \\
\text { mencari data } \\
\text { yang dicari }\end{array}$ & $\begin{array}{c}\text { Sistem akan } \\
\text { mencari data } \\
\text { yang dicari }\end{array}$ & Diterima \\
\hline
\end{tabular}


c. Pengujian terhadap Form Input Nilai

Pengujian terdadap form input nilai disajikan pada tabel 3.

Tabel 3. Pengujian terdadap Form Input Nilai

\begin{tabular}{|c|c|c|c|c|c|}
\hline NO & Skenario Pengujian & Test Case & $\begin{array}{c}\text { Hasil yang } \\
\text { diharapkan }\end{array}$ & $\begin{array}{c}\text { Hasil } \\
\text { Pengujian }\end{array}$ & Diterima \\
\hline 1. & Isi nilai pegawai & $\begin{array}{c}\text { Data masuk ke } \\
\text { form isian } \\
\text { nilai }\end{array}$ & $\begin{array}{c}\text { Pengisian } \\
\text { sesuai harapan }\end{array}$ & $\begin{array}{l}\text { Pengisian } \\
\text { sesuai } \\
\text { harapan }\end{array}$ & Diterima \\
\hline 2. & Klik tombol simpan & $\begin{array}{l}\text { Data disimpan } \\
\text { masuk ke } \\
\text { database dan } \\
\text { muncul pesan } \\
\text { data berhasil } \\
\text { disimpan }\end{array}$ & $\begin{array}{c}\text { Tombol } \\
\text { simpan sesuai } \\
\text { yang } \\
\text { diharapkan }\end{array}$ & $\begin{array}{c}\text { Tombol } \\
\text { simpan } \\
\text { sesuai yang } \\
\text { diharapkan }\end{array}$ & diterima \\
\hline 3. & Klik tombol hapus & $\begin{array}{c}\text { Data di } \\
\text { database } \\
\text { terhapus dan } \\
\text { muncul pesan } \\
\text { data berhasil } \\
\text { di hapus }\end{array}$ & $\begin{array}{c}\text { Tombol hapus } \\
\text { sesuai yang } \\
\text { diharapkan }\end{array}$ & $\begin{array}{c}\text { Tombol } \\
\text { hapus sesuai } \\
\text { yang } \\
\text { diharapkan }\end{array}$ & diterima \\
\hline 4. & Klik tombol cari & $\begin{array}{c}\text { Admin } \\
\text { mencari data } \\
\text { yang } \\
\text { diinginkan }\end{array}$ & $\begin{array}{l}\text { Sistem akan } \\
\text { mencari data } \\
\text { yang dicari }\end{array}$ & $\begin{array}{l}\text { Sesuai } \\
\text { harapan }\end{array}$ & Diterima \\
\hline
\end{tabular}

\section{KESIMPULAN}

\subsection{Kesimpulan}

Berdasarkan penelitian yang telah dilakukan maka didapatkan beberapa kesimpulan sebagai berikut:

a. Pemilihan Pegawai Teladan yang masih berjalan secara menual dan belum adanya metode yang dijadikan dasar dalam perhitungan nilai - nilai yang didapat oleh pegawai. Perhitungan nilai yang masih manual dan membutuhkan waktu yang lama dalam proses perhitungan mengakibatkan ketidak efisiennan waktu.

b. Sistem pendukung keputusan pemilihan pegawai teladan menggunakan metode SAW (Simple Additive Weighting) berbasis web dapat membantu pengambilan keputusan dalam pemilihan pegawai teladan pada Dinas Penanaman Modal Dan Pelayanan Terpadu Satu Pintu Kabupaten Kebumen.

c. Sistem pendukung keputusan pemilihan pegawai teladan menggunakan metode SAW (Simple Additive Weighting) berbasis web menghasilkan nilai kinerja (Profesional, Religius, Inovatif, Komitmen, Akun Tabel) untuk masing-masing Pegawai sebagai ukuran kinerjanya.

\subsection{Saran}

Harapan dalam perancangan sistem pendukung keputusan pemilihan pegawai teladan menggunakan metode SAW (Simple Additive Weighting) berbasis web di Dinas Penanaman Modal dan Pelayanan Terpadu Satu Pintu Kabupaten Kebumen. Beberapa saran untuk pengembangan sistem adalah sebagai berikut:

a. Perlu dilakukan sosialisasi dan training kepada bagian terkait terutama pada Subbagian Kepegawaian dan umum sebagai admin, agar sistem informasi dapat dimanfaatkan dengan baik.

b. Perlu adanya pengembangan sistem menjadi lebih baik lagi agar keamanan data dapat lebih terjaga.

\section{REFERENSI}

1. Endang, Marsudi. "Pengaruh komitmen organisasi dan gaya kepemimpinan terhadap hubungan antara partisipasi anggaran dan kinerja manajerial." LANTIP 2.01 (2012).

2. Farisi, P. (2011). Proyek Membuat Website Jejaring Sosial Dengan Joomla. Yogyakarta: Lokomedia.

3. Jogiyanto, H.M. (2005).Analisis dan Desain Sistem Informasi.Andi:Yogyakarta.

4. Kusrini. 2007. Konsep dan Aplikasi Sistem Pendukung Keputusan. Penerbit Andi, Yogyakarta 
5. Kusumadewi, Sri., Hartati, S., Harjoko, A., dan Wardoyo, R. (2006). Fuzzy Multi-Attribute Decision Making (FUZZY MADM). Yogyakarta: Penerbit Graha Ilmu.

6. MARIMIN, Ir. Teknik dan Aplikasi Pengambilan Keputusan Kriteria Majemuk. Bogor: Grasindo, 2004.

7. Mulyanto, Agus.(2009).Sistem Informasi Konsep dan Analisis.Pustaka Pelajar:Yogyakarta.

8. Munawar.(2005). Pemodelan Visual dengan UML.Grahailmu:Yogyakarta. Al Fatta, Hanif.(2007). Analisis dan Perancangan Sistem Informasi.Andi:Yogyakarta.

9. Pahlevy, Randy, Tesar. 2010. Rancang Bangun Sistem pendukung Keputusan Menentukan penerima Beasiswa dengan Menggunakan metode Simpele Additive Weighting (SAW).

10. Wibowo, Yessica. (2009). Perancangan dan Implementasi Penentuan Most Valuable Player (MVP) Pada Pertandingan Bola Basket. Salatiga: FTI UKSW.

11. http://sitiannisa49.blogspot.co.id/2015/06/metode- ahp-dalam-spk.html (senin,30/09/2017 13:04)

12. http://widuri.raharja.info/index.php?title=S1114465646 (senin,30/09/2017 23:34)

13. Waluyo, A., \& Santoso, S. B. (2018). Perancangan Sistem Informasi Geografis Pariwisata Berbasis Web Di Dinas Kepemudaan Dan Olahraga Dan Pariwisata Kabupaten Kebumen. Jurnal E-Komtek (ElektroKomputer-Teknik), 2(1), 23-34.

14. Waluyo, A., \& Irfandi, N. F. (2017). Employee Information System Using Ahp (Analytical Hierarchy Process) Method In Dinas Of Investment And Integrated Services One Door Of Kebumen District. Jurnal E-Komtek (Elektro-Komputer-Teknik), 1(1), 12-28.

15. Waluyo, Ari, "Android-Based Core Fiber Optic Management Information System Design In PT. Telkom Kebumen." IJISTECH (International Journal of Information System \& Technology) 3.1 (2019): 37-42.

16. Waluyo, A. Perancangan Website Dinas Pendidikan Pemuda Dan Olah Raga (Studi Kasus Dinas Pendidikan Pemuda Dan Olah Raga Kabupaten Kebumen). J-SAKTI (Jurnal Sains Komputer dan Informatika), 1(2), 186-196. 2017. 